\title{
AVALIAÇÃO DA COMPACIDADE, FUNCIONALIDADE E FLEXIBILIDADE EM HABITAÇÕES DE DIMENSÕES REDUZIDAS - ESTUDOS DE CASO EM EDIFÍCIOS DE FLORIANÓPOLIS-SC
}

CLÁUDIA VASCONCELOS, Dra. | UNIFESSPA

FERNANDO BARTH, Dr. | UFSC

\section{INTRODUÇÃO}

Esta pesquisa avaliou as habitações de dimensões reduzidas em edifícios multifamiliares, por meio de análise da compacidade, funcionalidade e flexiilidade arquitetônica.

O crescimento na oferta dessa categoria com área útil cada vez menor no mercado imobiliário brasileiro (SECOVI-SP, 2016) e, em particular na área de estudo, parte insular de Florianópolis.

As dimensões reduzidas dessa categoria habitacional podem ser compensadas pela dinâmica de uso de móveis com multifuncionalidade e articuláveis para assumir diferentes funções no decorrer do cotidiano doméstico, de forma sequenciada, simultânea ou periódica.

A pesquisa direcionou-se somente as unidades residenciais em edificação multifamiliar vertical e licenciadas por órgão regulador da prefeitura municipal e em conformidade com leis vigentes (FLORIANÓPOLIS, 2014 e 2000).

\section{MÉTODOS}

O estudo analisou a oferta de 391 projetos aprovados para novas construções no período de 2010 a 2014, totalizando a área construída de $2.667 .320 \mathrm{~m}^{2}$. Essa oferta compreende 14.988 unidades residenciais, sendo 1.614 de habitações com dimensões reduzidas e concentração de funções.

A pesquisa buscou aplicar métodos para avaliar essa categoria habitacional, identificando aspectos conceituais e requisitos mínimos, assim como a detecção de conflitos e desacordo com o Código de Obras (FLORIANÓPOLIS, 2000). Os métodos buscaram analisar a compacidade, a funcionalidade e a flexibilidade arquitetônica, em seis estudos de caso.

\section{RESULTADOS}

Os resultados mostram que os espaços com dimensões reduzidas induzem a sobreposição de usos, por meio de mobiliário e equipamentos com multifuncionalidade, de modo a atender a diversidade das atividades domésticas.

Os espaços, com dimensionamento reduzido, frequentemente restringem a usabilidade, diminuindo o desempenho funcional e a flexibilidade arquitetônica. Também, observou-se que a flexibilidade arquitetônica tem sido pouco explorada nos processos projetuais contemporâneos. E que pode ser ampliada pelas possibilidades de transformações da unidade e dos elementos construtivos, constituindo a base para a personalização e adequação dos espaços às necessidades mutáveis dos usuários.

\section{REFERÊNCIAS}

FLORIANÓPOLIS. Lei Complementar no 482, de 17 de janeiro de 2014. Institui o Plano Diretor de Urbanismo. Disponível em: < https://bit.ly/2yrfHLG > Acesso em: 25 mar 2020.

FLORIANÓPOLIS. Lei Complementar n 60, de 11 de maio de 2000. Institui o Código de Obras e Edificações e dá outras providências. Disponível em: <http://leismunicipa.is/ nopal>. Acesso em: 25 out 2013.

SINDICATO DAS EMPRESAS DE COMPRA, VENDA, LOCAÇÃO E ADMINISTRAÇÃO DE IMÓVEIS RESIDENCIAIS E COMERCIAIS DE SÃO PAULO. SECOVI-SP. Anuário do Mercado Imobiliário 2016. Secovi-SP (Sindicato da Habitação): São Paulo, 2016. Disponível em: <https://goo. gl/CKBr7b>. Acesso em: 30 jan. 2017.

\section{AGRADECIMENTOS}

A pesquisa recebeu auxílio financeiro de agência de fomento e agradece a Fundação de Amparo à Pesquisa do Estado do Amazonas, vinculada ao Governo do Estado do Amazonas, por possibilitar a sua realização. 
